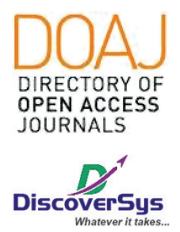

Published by DiscoverSys

\section{Perbandingan efektivitas teknik modifikasi dan konvensional pada operasi open pyelolithotomy batu staghorn}

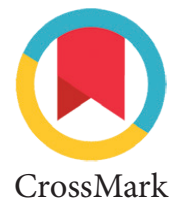

\author{
I Gede Hendra Sucipta, ${ }^{1 *}$ Anak Agung Gde Oka, ${ }^{2}$ I Gede Raka Widiana ${ }^{3}$
}

\title{
ABSTRACT
}

Background: Open pyelolithotomy for staghorn stone patient management has a high stone-free rate. The disadvantages of open pyelolithotomy include aesthetics and postoperative complications, so a breakthrough to reduce these complications is needed, which can be achieved by doing modified open pyelolithotomy. Objective: To compare the modified and conventional open pyelolithotomy techniques according to the duration of operation, the volume of surgical bleeding, pain, and post-operative drop in hemoglobin $(\mathrm{Hb})$. Method: A quasi-experimental study with twenty-two samples of staghorn stone patients was collected from 0ctober 2016 to October 2017. Parametric tests were used as data were normally distributed and homogeneous. The independent t-test was used to compare each measured parameter according to the type of operation. Analysis of covariance (ANCOVA) was used to control the variables of age, gender, and body mass index (BMI).
Result: The modified technique had a shorter operating duration than the conventional method $(p<.05)$. The volume of surgical bleeding in the modified technique was lower compared to the conventional technique $(p<.05)$. Pain scores in the modified technique were lower than the conventional technique $(p<.05)$. The drop in Hb levels in the modified technique was lower than the conventional technique $(p<.05)$. Analysis using ANCOVA found that the type of operation has a direct effect on the duration of operation, volume of surgical bleeding, and post-operative pain.

Conclusion: The modified open pyelolithotomy technique was more effective than the conventional open pyelolithotomy technique based on the duration of operation, the volume of surgical bleeding, and post-operative pain scale. In this study, it was found that the drop in $\mathrm{Hb}$ levels was not directly affected by the type of surgery.

Keywords: Staghorn stone, modified open pyelolithotomy, conventional open pyelolithotomy.

Cite This Article: Sucipta, I.G.H., Oka, A.A.G, Widiana, I.G.R. 2019. Perbandingan efektivitas teknik modifikasi dan konvensional pada operasi open pyelolithotomy batu staghorn. Intisari Sains Medis 10(1): 120-124. D0I: 10.1556/ism.v10i1.318

${ }^{1}$ Residen Bedah Umum,Fakultas Kedokteran Universitas Uddayana, RSUP Sanglah, Bali, Indonesia

${ }^{2}$ Bagian Urologi, Departemen Bedah, Fakultas Kedokteran Universitas Udayana, RSUP Sanglah, Bali, Indonesia

${ }^{3}$ Bagian IImu Penyakit Dalam, Fakultas Kedokteran Universitas Udayana, RSUP Sanglah, Bali, Indonesia

*Korespondensi:

I Gede Hendra Sucipta; Residen Bedah Umum, Fakultas Kedokteran Universitas Udayana, RSUP Sanglah, Bali, Indonesia

gede.hendra.sucipta@gmail.com

Received: 2018-09-30

Accepted: 2018-10-13

Published: 2019-04-01
Latar Belakang: Open pyelolithotomy sebagai modalitas terapi pasien batu staghorn mempunyai angka bebas batu yang tinggi. Modalitas ini memiliki kelemahan yaitu dari segi estetika dan komplikasi paska operasi, sehingga diperlukan terobosan untuk mengurangi komplikasi tersebut. Salah satu cara untuk menguranginya adalah dengan melakukan tindakan open pyelolithotomy yang dimodifikasi. Tujuan: Membandingkan teknik modifikasi dan konvensional dari open pyelolithotomy berdasarkan durasi operasi, volume perdarahan, skala nyeri, dan penurunan hemoglobin ( $\mathrm{Hb})$ paska operasi.

Metode: Ini adalah studi kuasi-eksperimental dengan 22 sampel pasien batu staghorn dikumpulkan dari Oktober 2016 hingga 0ktober 2017. Data pada penelitian ini terdistribusi normal dan homogen sehingga digunakan uji parametrik. Uji statistik independent $t$-test digunakan untuk membandingkan masing - masing parameter yang diukur berdasarkan kelompok jenis operasi. Uji analysis of covariate
(ANCOVA) digunakan untuk mengontrol variabel usia, jenis kelamin, dan indeks massa tubuh (IMT).

Hasil: Teknik modifikasi memiliki durasi operasi lebih singkat dibandingkan konvensional $(p<.05)$. Volume perdarahan pada teknik modifikasi lebih rendah dibandingkan konvensional $(p<.05)$. Skala nyeri pada teknik modifikasi lebih rendah dibandingkan dengan konvensional $(\mathrm{p}<.05)$. Penurunan kadar Hb pada teknik modifikasi lebih rendah dibandingkan dengan teknik konvensional $(p<.05)$. Pada uji ANCOVA didapatkan jenis operasi berpengaruh langsung terhadap durasi operasi, volume perdarahan, dan skala nyeri paska operasi.

Simpulan: Teknik modifikasi lebih efektif dibandingkan konvensional berdasarkan durasi operasi, volume perdarahan, dan skala nyeri. Tingkat penurunan kadar $\mathrm{Hb}$ pada penelitian ini tidak dipengaruhi secara langsung oleh jenis operasi. 


\section{LATAR BELAKANG}

Batu staghorn memiliki angka kejadian mencapai $1-5 \%$ dari populasi orang dewasa di negara industri. Di Amerika Serikat, kejadian penyakit batu saluran kemih ini mencapai $>400.000$ orang dengan insiden tertinggi terjadi pada usia dekade ketiga sampai keenam. Angka kejadian pada lakilaki 1.5 - 2.5 kali lebih tinggi dari wanita, dan pada orang kulit putih 5 kali lebih tinggi di bandingkan dengan orang kulit hitam. ${ }^{1}$

Salah satu metode penatalaksanaan batu staghorn adalah open pyelolithotomy. Prosedur ini dilakukan sebanyak $1.5 \%$ dari seluruh penatalaksanaan batu staghorn di negara berkembang. Di Amerika Serikat, pada tahun 2000 sebanyak $2 \%$ pasien dilakukan prosedur open pyelolithotomy. Pada dekade terakhir rasio prosedur open pyelolithotomy dilaporkan $26 \%$ pada rumah sakit rujukan tersier di Pakistan, dan 3-5\% di Amerika Serikat. $^{2}$

Open pyelolithotomy masih memiliki peranan sebagai pilihan modalitas terapi pasien dengan batu staghorn dan berhubungan dengan angka bebas batu yang tinggi.

Hellstrom menggambarkan teknik "pyelolithotomy in situ" dengan cara mengeluarkan batu dari pelvis dan kaliks tanpa membebaskan ginjal. ${ }^{3}$

Teknik modifikasi open pyelolithotomy adalah prosedur operasi mengeluarkan batu staghorn tanpa membuka fascia gerota secara keseluruhan. Teknik ini hanya membuka sebagian fascia gerota dengan teknik laparaskopik sehingga mengurangi komplikasi yang mungkin terjadi. Keunggulan dari teknik ini adalah menyederhanakan prosedur yang rumit dan memberikan hasil yang baik dengan morbiditas yang minimal.

Berdasarkan hal tersebut perlu dilakukan penelitian untuk membandingkan teknik modifikasi dan konvensional dari prosedur open pyelolithotomy. Penelitian ini bertujuan untuk membandingkan durasi operasi, volume perdarahan, skala nyeri, dan penurunan kadar haemoglobin paska operasi dari kedua teknik tersebut.

\section{METODE}

Ini merupakan studi kuasi - eksperimental dan dilakukan di Sub-Bagian Bedah Urologi RSUP Sanglah Denpasar yang dimulai pada Oktober 2016 hingga Oktober 2017. Kriteria inklusi pada penelitian ini adalah pasien batu staghorn yang menjalani operasi open pyelolithotomy di RSUP Sanglah Denpasar dengan usia 30-60 tahun. Sampel akan dibagi menjadi 2 kelompok, yang pertama adalah pasien batu staghorn dengan teknik modifikasi dan kedua dengan teknik konvensional. Total sampel sebanyak 22 orang dengan pembagian masing-masing kelompok 11 orang. Data mengenai durasi operasi, volume perdarahan, skala nyeri, dan penurunan kadar Hb paska operasi akan dibandingkan diantara kedua teknik tersebut. Durasi operasi dihitung dengan satuan menit, volume perdarahan dengan satuan $\mathrm{ml}$, skala nyeri dengan visual analog score (VAS) dan kadar $\mathrm{Hb}$ diukur dengan satuan $\mathrm{g} / \mathrm{dL}$.

Pada teknik operasi open pyelolithotomy konvensional, pengambilan batu dilakukan dengan cara membuka fascia gerota secara keseluruhan, sedangkan pada teknik modifikasi, fascia gerota hanya dibuka pada daerah pengambilan batu dengan teknik laparaskopik.

Data karakterisitik pasien dianalisis secara deskriptif untuk perbandingan antar kelompok. Data numerik ditampilkan dalam bentuk rerata \pm standar deviasi (SD) sedangkan data kategorikal ditampilkan dalam bentuk frekuensi relatif (jumlah persen). Hasil analisis akan ditampilkan menggunakan tabulasi distribusi untuk menilai komparabilitas antar kelompok.

Pengujian normalitas dan homogenitas data akan dilakukan terlebih dahulu menggunakan Shapiro Wilk Test dan Levene's Test. Bila didapatkan distribusi data normal dan homogen maka dilakukan uji tes parametrik Independent T Test.

Uji Analysis of Covariance (ANCOVA) dilakukan untuk mengetahui pengaruh langsung teknik modifikasi dan konvensional terhadap variabel durasi operasi, volume perdarahan, skala nyeri, dan penurunan kadar Hb paska operasi dengan mengontrol variabel usia, jenis kelamin, dan IMT.

\section{HASIL}

Karakteristik pasien pada penelitian ini dapat dilihat dengan lengkap pada Tabel 1 . Usia, jenis kelamin, IMT, dan lokasi batu staghorn memiliki komposisi yang tidak berbeda antar kedua kelompok.

Uji normalitas data dengan Shapiro-wilk dan uji homogenitas dengan Levene test dilakukan sebelum melakukan uji bivariat. Hasil pengujian dapat dilihat dengan lengkap pada Tabel 2. Seluruh variabel pada penelitian ini memiliki nilai $W$ dan $F_{\text {Levene }}>0.05$ yang menunjukan data terdistribusi normal dan homogen sehingga dapat dilanjutkan dengan uji independent $T$ test yang ditampilkan pada Tabel 3.

Terdapat perbedaan yang signifikan pada durasi operasi antara teknik modifikasi dan konvensional. Durasi operasi pada teknik modifikasi 45.7 menit lebih singkat dibandingkan dengan konvensional. Teknik modifikasi menyebabkan perdarahan dengan volume lebih rendah dibandingkan dengan konvensional $(p<.05)$. Jumlah perdarahan pada 
Tabel 1 Karakteristik dasar pasien

\begin{tabular}{lcc}
\hline & \multicolumn{2}{c}{ Teknik operasi } \\
\cline { 2 - 3 } Variabel & Modifikasi $(\mathbf{n = 1 1 )}$ & Konvensional (n=11) \\
\hline Usia, tahun (mean \pm SD) & $54 \pm 5.7$ & $49.8 \pm 6.2$ \\
Jenis kelamin (\%) & & \\
Laki-laki & $8(72.8 \%)$ & $7(63.6 \%)$ \\
Perempuan & $3(27.2 \%)$ & $4(36.4 \%)$ \\
BMI (mean \pm SD) & $27.4 \pm 5.8$ & $26.5 \pm 4.3$ \\
Diagnosis (\%) & & \\
Batu staghorn dextra & $8(72.8 \%)$ & $7(63.6 \%)$ \\
Batu staghorn sinistra & $3(27.2 \%)$ & $4(36.4 \%)$ \\
\hline
\end{tabular}

Tabel 2 Hasil uji normalitas dan homogenitas data

\begin{tabular}{lcc}
\hline Variabel & $\boldsymbol{W}$ & $\boldsymbol{F}_{\text {Levene }}$ \\
\hline Durasi operasi & .52 & .57 \\
Volume perdarahan & .12 & .05 \\
Skala nyeri & .08 & .56 \\
Penurunan kadar Hb & .59 & .17 \\
\hline
\end{tabular}

Tabel 3 Perbedaan rerata durasi operasi, volume perdarahan, skala nyeri, dan penurunan kadar $\mathrm{Hb}$ antara teknik modifikasi dan konvensional

\begin{tabular}{|c|c|c|c|c|c|}
\hline \multirow[b]{2}{*}{ Variabel } & \multicolumn{2}{|c|}{ Jenis operasi } & \multirow[b]{2}{*}{$\begin{array}{c}\text { Beda } \\
\text { rerata }\end{array}$} & \multirow[b]{2}{*}{$\mathrm{Cl} 95 \%$} & \multirow[b]{2}{*}{ p-value } \\
\hline & $\begin{array}{l}\text { Modifikasi } \\
\text { (Mean } \pm \text { SD) }\end{array}$ & $\begin{array}{c}\text { Konvensional } \\
\text { (Mean } \pm \text { SD) }\end{array}$ & & & \\
\hline Durasi operasi (menit) & $81.8 \pm 15.2$ & $127.5 \pm 18.9$ & 45.7 & $30.5-60.9$ & $0.000^{*}$ \\
\hline Vol. perdarahan (ml) & $68.2 \pm 27.3$ & $185.9 \pm 53.6$ & 117.7 & $79.9-155.5$ & $0.000^{*}$ \\
\hline Skala nyeri (VAS) & $3.2 \pm 0.9$ & $4.6 \pm 0.9$ & 1.4 & $0.6-2.2$ & $0.001^{\star}$ \\
\hline Hb pre-op (g/dL) & $13.2 \pm 2.1$ & $13.4 \pm 1.6$ & 0.2 & $-1.5-1.9$ & 0.808 \\
\hline Hb post-op (g/dL) & $12.6 \pm 2.1$ & $12.4 \pm 1.5$ & 0.2 & $-1.8-1.4$ & 0.805 \\
\hline Penurunan $\mathrm{Hb}(\mathrm{g} / \mathrm{dL})$ & $0.64 \pm 0.47$ & $1.03 \pm 0.53$ & 0.39 & $0.6-1.7$ & $0.000^{*}$ \\
\hline
\end{tabular}

${ }^{*} \mathrm{P}<0.05$ menunjukkan terdapat perbedaan yang bermakna secara statistik

Tabel 4 Uji ANCOVA dengan mengontrol variabel usia, jenis kelamin, dan IMT

\begin{tabular}{lcc}
\hline Variabel Dependen & Adjusted $\boldsymbol{F}$ & Adjusted $\boldsymbol{p}$-value \\
\hline Durasi operasi & 38.37 & .000 \\
Volume perdarahan & 51.59 & .000 \\
Skala nyeri paska operasi & 10.92 & .004 \\
Penurunan kadar Hb paska operasi & 3.307 & .088 \\
\hline
\end{tabular}

teknik konvensional lebih banyak $117.7 \mathrm{ml}$ dibandingkan dengan teknik modifikasi.

Pada skala nyeri, teknik konvensional menyebabkan derajat nyeri yang lebih tinggi dibandingkan teknik modifikasi. Perbedaan antar kedua kelompok ini signifikan dengan perbedaan rerata 1.4 . Pada Tabel 3 dapat dilihat bahwa kadar $\mathrm{Hb}$ sebelum operasi pada kedua kelompok tidak memiliki perbedaan yang signifikan menandakan kondisi yang sama sebelum diberikan terapi. Setelah dilakukan intervensi, didapatkan teknik modifikasi lebih sedikit menurunkan kadar $\mathrm{Hb}$ dibandingkan teknik konvensional $(p<.05)$.

Pada Tabel 4 disajikan data hasil uji ANCOVA yang menunjukan pengaruh langsung dari teknik yang digunakan terhadap durasi operasi, volume perdarahan, skala nyeri, dan penurunan kadar $\mathrm{Hb}$ paska operasi dengan mengontrol variabel usia, jenis kelamin dan IMT. 
Pada penelitian ini ditemukan bahwa teknik operasi yang digunakan mempengaruhi durasi operasi, volume perdarahan, dan skala nyeri paska operasi secara langsung $(p<.05)$. Namun, penurunan kadar hemoglobin paska operasi, tidak dipengaruhi secara langsung oleh teknik operasi yang digunakan $(p>.05)$

\section{PEMBAHASAN}

Open pyelolithotomy batu staghorn dilaporkan sebanyak $1.5 \%$ dari seluruh manajemen operatif batu ginjal di negara berkembang. Di Amerika Serikat pada tahun 2000 sebanyak 2\% pasien dilakukan prosedur operatif open pyelolithotomy batu staghorn. Pada dekade terakhir prevalensi prosedur operasi open pyelolithotomy batu staghorn dilaporkan $26 \%$ pada rumah sakit rujukan tersier di Pakistan, dan 3-5\% di Amerika Serikat. ${ }^{2}$

Khalaf et $a l^{4}$ mendeskripsikan bahwa teknik operasi open pyelolithotomy mempunyai angka bebas batu sebesar 90\%. Sedangkan Yasser et al menjelaskan angka bebas batu pada Laparascopic Pyelolithotomy (LPL) sebesar 88\% dan Percutaneous Nephrolithotomy (PNL) sebesar 82\%. Penelitian oleh Ghani et al $^{6}$ menlaporkan angka bebas batu pada operasi Robotic Pyelolithotomy sebesar 96\%. Ini menunjukkan bahwa teknik operasi open pyelolithotomy mempunyai angka bebas batu yang tinggi sehingga masih memiliki peranan untuk penatalaksanaan pasien dengan batu staghorn.

Pada penelitian ini didapatkan 22 sampel penelitian (11 sampel teknik modifikasi dan 11 sampel teknik konvensional) dengan jenis kelamin laki-laki sebanyak 15 subyek (68.2\%) dan perempuan sebanyak 7 subyek (31.8\%) dengan rasio 2.1:1. Penelitian di India mendapatkan angka kejadian batu staghorn antara laki-laki dan perempuan dengan rasio 1.82:1, Iran dengan rasio $1.15: 1$, Thailand dengan rasio 1.6:1, dan Iraq dengan rasio 2.5:1.7 Dari hasil penelitian tersebut didapatkan bahwa angka kejadian batu staghorn pada laki-laki sekitar 1.5-2.5 kali lebih banyak dibandingkan perempuan.

Pada penelitian ini didapatkan IMT pada teknik modifikasi dan konvensional adalah 27.4 dan 26.5 yang menunjukan kondisi preobesitas. Hal ini sesuai dengan hasil penelitian Lee et $a l^{8}$ yang melaporkan IMT sebesar 25.1 pada sampel penelitiannya.

Usia pada sampel penelitian ini berkisar antara 30-60 tahun dengan rerata pada kelompok teknik modifikasi sebesar 54 tahun dan pada kelompok teknik konvensional sebesar 49.8 tahun. Hal ini sesuai dengan beberapa penelitian yang menyatakan bahwa prevalensi penyakit batu ginjal meningkat seiring bertambahnya umur sekitar 30-60 tahun dan menurun setelah umur 60 tahun.,
Pada penelitian ini rerata durasi operasi dengan teknik modifikasi adalah 81.8 menit sedangkan teknik konvensional adalah 127.5 menit. Celik et al ${ }^{10}$ menjelaskan bahwa pada operasi open pyelolithotomy konvensional didapatkan rerata durasi operasi 115 menit. Patloo et al ${ }^{11}$ juga melaporkan pada penelitian dengan 30 pasien batu staghorn yang menjalani operasi open pyelolithotomy konvensional didapatkan rerata durasi operasi 94.43 menit. Altin et $a l^{12}$ menjelaskan pada operasi open pyelolithotomy konvensional didapatkan durasi operasi ratarata selama 116 menit. Penelitian oleh Singal et al ${ }^{13}$ menunjukkan durasi operasi LPL adalah 84.2 menit sedangkan Ghani et al ${ }^{6}$ melaporkan durasi operasi Robotic Pyelolithotomy selama 128 menit. Hasil dari beberapa penelitian ini menunjukkan bahwa ada perbedaan rerata durasi operasi antara teknik modifikasi dengan teknik konvensional dimana rerata durasi operasi dengan teknik modifikasi lebih cepat dibandingkan teknik konvensional. Teknik LPL yang dilakukan oleh Singal et al ${ }^{13}$ memiliki durasi yang hampir sama dengan teknik modifikasi yang dilakukan. Hal ini dimungkinkan karena kedua teknik ini menggunakan teknik laparoskopik sehingga durasi operasi menjadi lebih cepat. Namun durasi operasi ini sangat dipengaruhi oleh kemampuan dan pengalaman dari operator.

Berdasarkan volume perdarahan, teknik modifikasi lebih sedikit menyebabkan perdarahan dengan rerata $68.2 \mathrm{ml}$ sedangkan volume perdarahan pada teknik konvensional $185.9 \mathrm{ml}$ dengan beda rerata $117.7 \mathrm{ml}$. Patloo et al ${ }^{11}$ menyebutkan bahwa volume perdarahan pada teknik open pyelolithotomy konvensional sebanyak $103 \mathrm{ml}$. Penelitian oleh Altin et $\mathrm{al}^{12}$ melaporkan perdarahan setelah dilakukan open pyelolithotomy konvensional sebanyak $70 \mathrm{ml}$. Celik et $a l^{10}$ melaporkan bahwa pada operasi open pyelolithotomy konvensional didapatkan rata-rata jumlah perdarahan sebanyak $50 \mathrm{ml}$. Penelitian lain oleh Singal et $a^{13}$ menunjukkan volume perdarahan operasi LPL sebanyak $63 \mathrm{ml}$, dan Ghani et al menunjukkan volume perdarahan operasi Robotic Pyelolithotomy sebanyak $38 \mathrm{ml}$. Volume perdarahan pada teknik konvensional dalam penelitian ini cukup banyak bila dibandingkan dengan penelitian lain. Teknik modifikasi pada juga memiliki volume perdarahan yang tidak jauh berbeda dengan Hasil dari penelitian ini menunjukkan terdapat perbedaan volume perdarahan antara teknik modifikasi dengan open pyelolithotomy konvensional dalam penelitian lain. Volume perdarahan ini tentu saja sangat berpengaruh pada kemampuan operator dalam mengatasi perdarahan yang terjadi.

Pada penelitian ini skala nyeri (VAS) paska operasi pada teknik modifikasi lebih kecil dibandingkan dengan teknik konvensional. Pada teknik 
modifikasi didapatkan skala nyeri 3.2 dan 4.6 pada teknik konvensional sehingga didapatkan beda rerata skala nyeri sebesar 1.4. Penelitian oleh Patloo et al, ${ }^{11}$ menemukan bahwa skala nyeri (VAS) paska operasi dari teknik konvensional sebesar 5.1. Singal et $a^{13}$ melaporkan skala nyeri (VAS) paska operasi LPL sebesar 2.6. Skala nyeri (VAS) paska operasi pada teknik modifikasi lebih tinggi bila dibandingkan dengan LPL. Hal ini dimungkinkan terjadi karena operasi LPL hanya membutuhkan insisi yang tidak terlalu besar sehingga trauma operasi menjadi kecil.

Penurunan kadar $\mathrm{Hb}$ ( $\mathrm{Hb}$ sebelum operasi - $\mathrm{Hb}$ sesudah operasi) pada teknik modifikasi sebesar $0.64 \mathrm{gr} / \mathrm{dL}$ dan penurunan kadar $\mathrm{Hb}$ (Hb sebelum operasi - Hb sesudah operasi) pada teknik konvensional sebesar $1.03 \mathrm{gr} / \mathrm{dL}$ dengan beda rerata $0.39 \mathrm{gr} / \mathrm{dL}$. Pada penelitian Zehri et al $^{14}$ menunjukkan kadar Hb sebelum operasi PNL 13.86 gr/dL dan kadar $\mathrm{Hb}$ paska operasi sebesar $12.18 \mathrm{gr} / \mathrm{dL}$ dengan selisih sebesar $1.68 \mathrm{gr} / \mathrm{dL}$. Hasil ini menunjukkan teknik operasi modifikasi lebih sedikit penurunan kadar Hb paska operasi dibandingkan teknik operasi konvensional dan PNL.

Pada hasil uji ANCOVA, didapatkan bahwa durasi operasi, volume perdarahan, dan skala nyeri berpengaruh langsung terhadap jenis operasi $(\mathrm{p}<0.05)$. Ini memperkuat hasil penelitian yang menunjukan bahwa teknik modifikasi lebih baik dibandingkan konvensional dari segi durasi operasi, volume perdarahan dan skala nyeri post-op. Namun, jenis operasi tidak berpengaruh langsung terhadap penurunan kadar $\mathrm{Hb}$ paska operasi $(\mathrm{p}>0.05)$. Sehingga penurunan kadar $\mathrm{Hb}$ yang cenderung lebih rendah pada teknik modifikasi, tidak sepenuhnya disebabkan oleh teknik modifikasi ini.

\section{KESIMPULAN}

Pada penelitian ini didapatkan teknik modifikasi lebih efektif dibandingkan dengan teknik konvensional berdasarkan durasi operasi, volume perdarahan, dan skala nyeri paska operasi. Penurunan kadar $\mathrm{Hb}$ pada teknik modifikasi lebih rendah dibandingkan konvensional, namun penurunan ini tidak sepenuhnya dipengaruhi oleh teknik tersebut.

\section{DAFTAR PUSTAKA}

1. Ferri FF. Urolithiasis in Clinical Advisor Instant Diagnosis and Treatment, Rhode Island. Department of Community Health Brown Medical School Providence. 2004. 893-95

2. Husseiny TE, Buchholz N. The role of open stone surgery. Arab J Urol. 2012 Sep; 10(3): 284-288. DOI: 10.1016/j. aju.2012.03.004

3. Woodhouse CR, Farrell CR, Paris AM, Blandy JP. The place of extended pyelolithotomy (Gil-Vernet Operation) in the management of renal staghorn calculi. Br J Urol. 1981 Dec;53(6):520-3. DOI: 10.1111/j.1464-410x.1981. tb03252.x

4. Khalaf I, Salih E, El-Mallah E, Farghal S, Abdul-Raouf A. The outcome of open renal stone surgery calls for limitation of its use: A single institution experience. African Journal of Urology. 2013;19:58-65. DOI: 10.1016/j. afju.2013.04.001

5. Haggag YM, Morsy G, Badr MM, Al Emam AB, Farid M, Etafy M. Comparative study of laparoscopic pyelolithotomy versus percutaneous nephrolithotomy in the management of large renal pelvic stones. Can Urol Assoc J. 2013 Mar-Apr;7(3-4):E171-5. DOI; 10.5489/cuaj.490

6. Swearingen R, Sood A, Madi R, Klaassen Z, Badani K, Elder JS et al. Zero-fragment Nephrolithotomy: A Multi-center Evaluation of Robotic Pyelolithotomy and Nephrolithotomy for Treating Renal Stones. European Urology. 2017 Dec;72(6):1014-1021. DOI: 10.1016/j. eururo.2016.10.021.

7. Sofia HN, Manickavasakam K, Walter TM. Prevalence and Risk Factors of Kidney Stone. Global Journal for Research Analysis. 2016;5(3):2277-8160.

8. Lee JK, Kim BS, Park YK. Predictive Factors for Bleeding During Percutaneous Nephrolithotomy. Korean J Urol. 2013 Jul; 54(7): 448-453. DOI: 10.4111/kju.2013.54.7.448

9. Romero V, Akpinar H, Assimos DG. Kidney Stones: A Global Picture of Prevalence, Incidence and Associated Risk Factors. Rev Urol. 2010 Spring-Summer; 12(2-3): e86-e96. DOI: 10.3909/riu0459

10. Celik H, Karazindiyanoglu S, Gokcen K, Kobaner M. One Year Experience of Urological Surgery with 99 cases in a State Hospital. J Turgut Ozal Med Cent. 2015; 22: 235-8

11. Patloo AM, Sarmast AH, Khan MA, Khan MA, Zaz M, Khan MA et al. Laparoscopic retroperitoneal pyelolithotomy and open pyelolithotomy: a comparative study. Turkish Journal of Urology. 2012; 38(4): 195-200. DOI: 10.5152/tud.2012.041

12. Altin S., Topaktas R., Akkoc A., Aydm C., Girgin R., Aydin Z.B., Yildirim K. 2016. Our Initial Experience with Laparoscopic Urologic Surgery, no. 43, pp.43-49

13. Singal R, Dhar S. Retroperitoneal laparascopic pyelolithotomy in renal pelvic stone versus open surgery-a comparative study. Clujul Med. 2018; 91(1): 85-91. DOI: 10.15386/cjmed-732.

14. Zehri AA, Biyabani SR, Siddiqui KM, Memon A. Triggers of blood transfusion in percutaneous nephrolithotomy. J Coll Physicians Surg Pak. 2011 Mar; 21(3): 138-41. DOI: 03.2011/JCPSP.138141

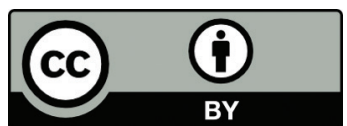

This work is licensed under a Creative Commons Attribution 